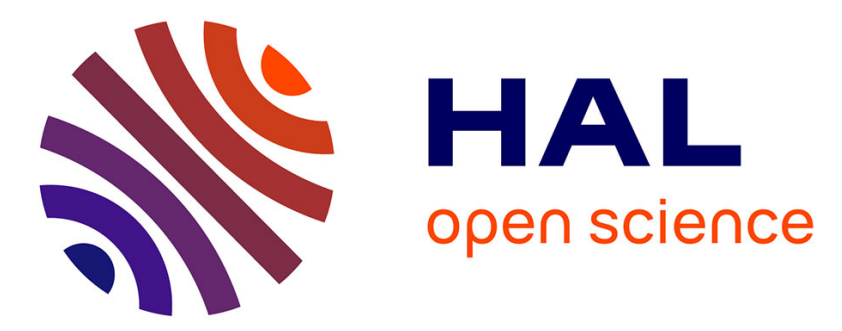

\title{
Disproportionation or combination? The termination of acrylate radicals in ATRP
}

\author{
Thomas G. Ribelli, Kyle F. Augustine, Marco Fantin, Pawel Krys, Rinaldo
}

Poli, K. Matyjaszewski

\section{To cite this version:}

Thomas G. Ribelli, Kyle F. Augustine, Marco Fantin, Pawel Krys, Rinaldo Poli, et al.. Disproportionation or combination? The termination of acrylate radicals in ATRP. Macromolecules, 2017, 50 (20), pp.7920-7929. 10.1021/acs.macromol.7b01552 . hal-01940158

\section{HAL Id: hal-01940158 \\ https://hal.science/hal-01940158}

Submitted on 1 Mar 2021

HAL is a multi-disciplinary open access archive for the deposit and dissemination of scientific research documents, whether they are published or not. The documents may come from teaching and research institutions in France or abroad, or from public or private research centers.
L'archive ouverte pluridisciplinaire HAL, est destinée au dépôt et à la diffusion de documents scientifiques de niveau recherche, publiés ou non, émanant des établissements d'enseignement et de recherche français ou étrangers, des laboratoires publics ou privés. 


\section{Disproportionation or Combination? The Termination of Acrylate Radicals in ATRP}

Thomas G. Ribelli, ${ }^{a}$ Kyle F. Augustine, ${ }^{a}$ Marco Fantin, ${ }^{a}$ Pawel Krys,${ }^{a}$ Rinaldo Poli, ${ }^{, b, c}$ Krzysztof Matyjaszewski ${ }^{\star a}$

aDepartment of Chemistry, Carnegie Mellon University, 4400 Fifth Avenue, Pittsburgh, Pennsylvania 15213, USA

${ }^{b}$ CNRS, LCC (Laboratoire de Chimie de Coordination), Université de Toulouse, UPS, INPT, 205 Route de Narbonne, BP 44099, F-31077, Toulouse Cedex 4, France Institut Universitaire de France, 1, rue Descartes, 75231 Paris Cedex 05, France

\section{ABSTRACT}

The termination of acrylate radicals in atom transfer radical polymerization (ATRP) can involve either conventional bimolecular radical termination (RT) or catalytic radical termination (CRT). These processes were investigated using a poly(methyl acrylate) $-\mathrm{Br}$ macroinitiator under different initial conditions tuned to change the RT/CRT ratio. The polymers, obtained from alkyl halide chain-end activation by $\left[\mathrm{Cu}^{\prime}(\mathrm{L})\right]^{+}(\mathrm{L}=\operatorname{tris}[2-$ (dimethylamino)ethyl]amine (Me6 ${ }_{6}$ TREN), tris(2-pyridylmethyl)amine (TPMA), or tris(3,5dimethyl-4-methoxy-2-pyridylmethyl)amine $\left(\mathrm{TPMA}^{* 3}\right)$ ) in the absence of monomer, were analyzed by size exclusion chromatography (SEC). RT-promoting conditions resulted in the increase of a shoulder with double molecular weight (MW) relative to the macroinitiator distribution, indicating that RT occurred predominantly via radical combination. Conversely, when CRT was promoted, the macroinitiator distribution did not shift, indicating a disproportionation-like pathway. The termination reactions for the TPMA system were further analyzed via PREDICI simulations, which showed the significant impact of mid-chain radicals, arising from backbiting, on the overall termination profile. In all cases, CRT and cross termination between secondary chain-end and tertiary mid-chain radicals contributed the most to the overall amount of terminated chains.

\section{INTRODUCTION}


Conventional radical polymerization (RP) and the recently developed reversibledeactivation radical polymerization (RDRP) methods have achieved tremendous success..$^{1-5}$ Versatility of the radical-based processes originates from facile experimental setup, wide range of reaction temperatures, and tolerance to functional groups, solvents, and impurities. Throughout the years, elementary reactions occurring in radical polymerizations have been identified and meticulously studied.6-11 This also led to development of sophisticated techniques allowing for the precise determination of rate coefficients. ${ }^{7,} 12-13$ In conventional RP, propagation and termination rate coefficients can be accurately measured using time-resolved electron paramagnetic resonance (EPR) spectroscopy coupled with single pulse pulsed laser polymerization technique (SPPLP). ${ }^{14-20}$ Although the kinetics of termination has been well studied, the mechanism of bimolecular termination is still a topic of some debate.

As shown in Scheme 1, bimolecular radical termination can occur via combination (Comb) or disproportionation (Disp), resulting in one chain with doubled molecular weight or two chains with a saturated and unsaturated chain end, respectively. The relative extent of these reactions depends on the nature of the radicals. Styrenes ${ }^{21-22}$ and acrylonitrile ${ }^{23}$ were suggested to primarily undergo coupling, while methacrylates undergo both Disp and Comb22, 24 . Acrylates, however, present a more complex, debated, and yet unresolved case. ${ }^{21,25-26}$ Recently, using radicals photo-generated from organotellurium macroinitiators, Yamago et al. suggested that acrylate radicals terminate predominantly $(99 \%)$ by disproportionation at room temperature. ${ }^{27}$ Most recently, Yamago et al has published on a surprising temperature and viscosity dependence on the termination mechanism of macro and small molecule RTe-(p)MMA and RTe-(p)St compounds with higher temperature increasing the fraction of combination and higher viscosities promoting combination. ${ }^{28}$ Because of this, we recently reported on a newly proposed tellanyl catalyzed disproportionation ${ }^{29}$ to rationalize their results. Asua et al. ${ }^{30}$ also suggested that acrylate radicals terminate via combination, but transfer reactions can also explain the surprising results reported by Yamago. Due to the relatively high reactivity of the acrylate radicals, both intermolecular ${ }^{31}$ and intramolecular (backbiting) ${ }^{32-33}$ transfer to polymer can occur. ${ }^{34-37}$ Such reactions lead to tertiary mid-chain radicals (MCR), which 
can terminate with another secondary propagating radical (SPR) or MCR. ${ }^{38}$ At higher temperatures, MCRs undergo radical migration ${ }^{39-40}$ and $\beta$-scission leading to macromonomers. ${ }^{41-43}$ Undoubtedly, transfer reactions are important for in-depth understanding of the termination mechanism of acrylates. This also holds true in RDRP techniques, where radical termination is suppressed.

\section{Radical Generation}

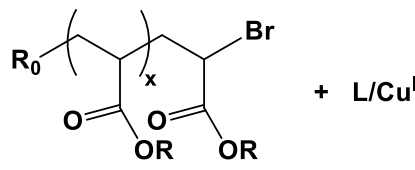

$\left(\mathbf{P}_{2}-\mathbf{X}\right)$
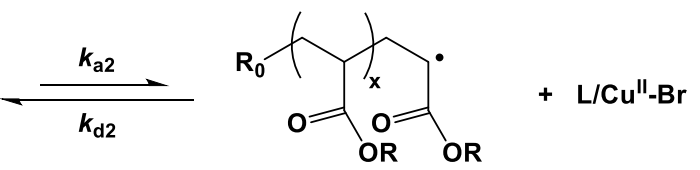

$\left(P_{2}^{*}\right)$

\section{Termination}

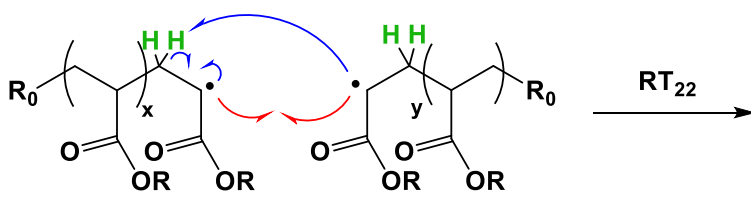

$\left(\mathbf{P}_{2}^{*}\right)$

$\left(\mathbf{P}_{2}^{*}\right)$

\section{Backbiting}

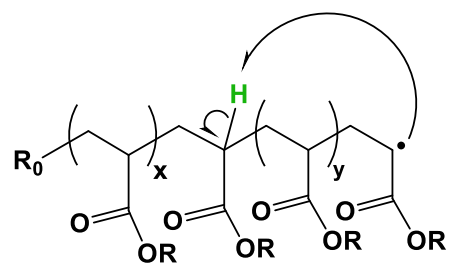

$\left(P_{2}^{*}\right)$
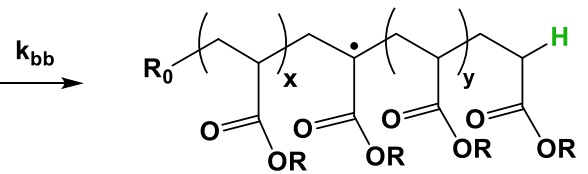

$\left(\mathbf{P}_{3}^{*}\right)$ disproportionation

$\left(P_{2}+P_{2}\right)$

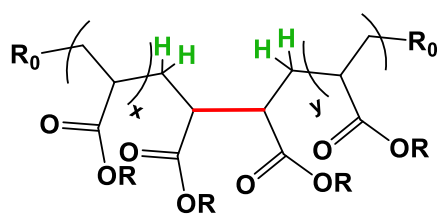

combination

$\left(\mathrm{P}_{2}-\mathrm{P}_{2}\right)$

Scheme 1 (Top) Pathways of bimolecular radical termination of two chain-end acrylate radicals $\left(\mathrm{P}_{2^{\bullet}}\right)$, proceeding either via disproportionation (blue) or combination (red); (bottom) formation of tertiary mid-chain radicals $\left(\mathrm{P}_{3} \cdot{ }^{\circ}\right.$ via backbiting and subsequent termination with another mid-chain radical or secondary chain-end radical, both resulting in disproportionated chains. ${ }^{38}$ 
RDRP methods such as reversible addition-fragmentation chain transfer (RAFT) polymerization and atom transfer radical polymerization (ATRP) can successfully control the polymerization of acrylate-based monomers..$^{35-36,44-47}$ The reactions can be conducted under mild conditions and are typically fast and efficient. However, ATRP systems with highly active catalysts ${ }^{48}$ present an additional side reaction in which acrylate radicals can reversibly coordinate to $\mathrm{L} / \mathrm{Cu}$ resulting in formation of a $\mathrm{L} / \mathrm{Cu}{ }^{l l}-\mathrm{P}_{\mathrm{n}}$ complex as shown in Scheme 2. ${ }^{49-51}$ This is related to organometallic mediated radical polymerization (OMRP) systems ${ }^{52}$, most common with cobalt complexes. ${ }^{53-56}$ The L/Cull-P $\mathrm{P}_{\mathrm{n}}$ species can then react with a second radical, leading to catalytic radical termination (CRT). ${ }^{57-58}$ Indeed, CRT has recently been shown to be the dominant mode of termination in ATRP of acrylate monomers. ${ }^{50,59}$ Despite the low overall amount of terminated chains $(<3 \%)$ in these reactions, the majority ( $\approx 90 \%)$ of these dead chains originated from CRT reactions, even when low amounts of $\mathrm{L} / \mathrm{Cu}$ ' were used.

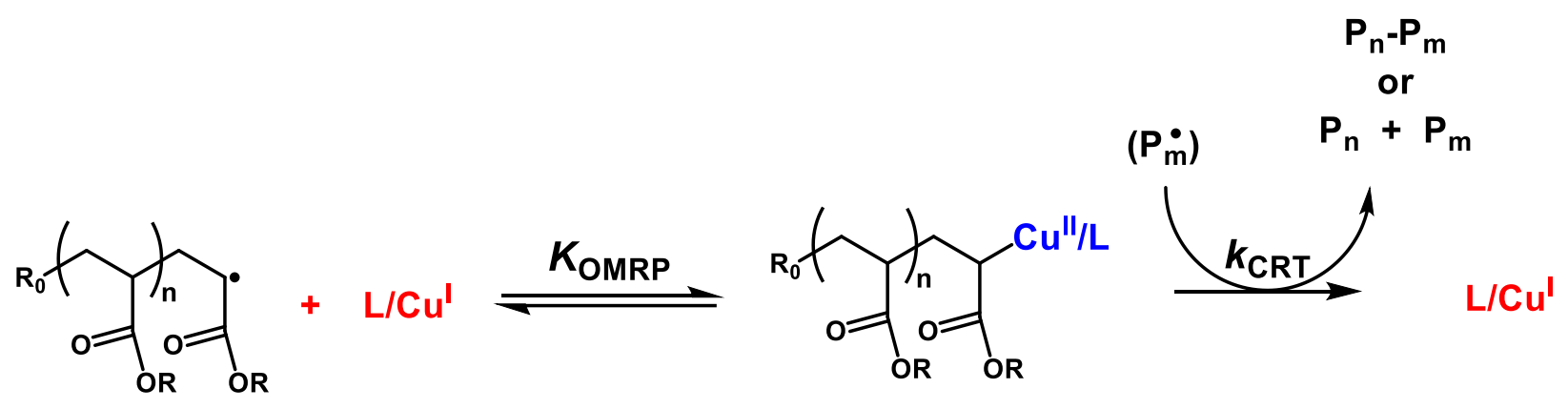

Scheme 2 Catalytic radical termination (CRT) of acrylates in the presence of $L / C u^{\prime}$ complexes.

Previously, we have reported that CRT gives disproportionation-like products with a tris(2pyridylmethyl)amine (TPMA) based system. ${ }^{50}$ Interestingly, Yamago et al. recently proposed $^{22}$ that using the tris[2-(dimethylamino)ethyl]amine (Me6TREN)-based system, termination gave products of doubled molecular weight via a proposed $\mathrm{Me}_{6}$ TREN/Cu ${ }^{\mathrm{II}}$ $(\mathrm{pMA})_{2}$ intermediate. Due to the ongoing debate involving the mechanism of bimolecular radical termination and contradictory results of CRT, we sought to obtain a better understanding of these two mechanisms of termination. Using three different $\mathrm{L} / \mathrm{Cu}$ catalytic systems, $\mathrm{L}=\mathrm{Me}_{6} \mathrm{TREN}$, TPMA and tris(3,5-dimethyl-4-methoxy-2pyridylmethyl)amine (TPMA*3), under controlled conditions, it is possible to reassess the 
products of CRT as well as obtain valuable information about the mechanism of conventional bimolecular radical termination.

One method of studying termination mechanisms is by generating chain-end radicals via activation of "living" macroinitiators. Using various initial conditions and catalytic systems, we were able to kinetically promote different contributions of conventional radical termination of chain-end radicals (RT) and catalytic radical termination (CRT). By analyzing the kinetics of termination and molecular weights of the resulting polymers, valuable mechanistic insights were obtained. According to Eq. 1, to increase the fraction of $\mathrm{RT}$ relative to CRT one can: a) decrease [L/Cull-X]o or b) increase the ATRP equilibrium constant (KATRP):

$\frac{\text { Rate }_{\mathrm{RT}}}{\text { Rate }_{\mathrm{CRT}}}=\frac{2 k_{\mathrm{t}}\left[\mathrm{P}_{\mathrm{n}} \cdot\right]^{2}}{2 k_{\mathrm{CRT}}\left[\mathrm{P}_{\mathrm{n}} \cdot\right]\left[\mathrm{L} / \mathrm{Cu}^{\mathrm{I}}\right]}=\frac{k_{\mathrm{t}}\left[\mathrm{P}_{\mathrm{n}} \cdot\right]}{k_{\mathrm{CRT}}\left[\mathrm{L} / \mathrm{Cu}^{\mathrm{I}}\right]}=\frac{k_{\mathrm{t}}\left[\mathrm{P}_{\mathrm{n}} \mathrm{X}\right]}{k_{\mathrm{CRT}}\left[\mathrm{L} / \mathrm{Cu}^{\mathrm{II}}-\mathrm{X}\right]} K_{\mathrm{ATRP}}$

Indeed, PREDICI simulations carried out at three different initial conditions confirmed the predictions from Eq 1. As shown in Figure 1, when using the same catalyst (i.e. same $K_{\text {ATRP), }} \mathrm{RT}_{22} / \mathrm{CRT}$ is higher for a) lower [PMA-Br]:[L/Cu'] ratio (1:1) and b) lower [L/Cu']. Note that $\mathrm{RT}_{22}$ refers to termination between secondary radicals. Figure 1 also shows the large variation of the $R T_{22} / C R T$ ratio with time. $R T_{22} / C R T$ is largest only at the very first instants when radical concentration is highest. Since the bimolecular termination of chain-end radicals depends on $[R \cdot]^{2}, R T_{22}$ dominates only during the very first milliseconds. Once the $\mathrm{L} / \mathrm{Cu}^{\prime \prime}-\mathrm{X}$ deactivator builds-up via the persistent radical effect (PRE), the [R•] is suppressed, thus significantly decreasing the rate of $R T_{22}$. After this initial "influx" of radicals, CRT dominates since $\left[\mathrm{Cu}^{\prime}\right]>\left[\mathrm{R}^{\cdot}\right]$ and thus a radical will preferentially coordinate to $\mathrm{L} / \mathrm{Cu}$ ' before terminating with a second radical. This is further shown under the most CRT-inducing conditions (green line), where additional deactivator is present from the beginning and a very small RT/CRT is observed, even at the onset of the reaction. This is because the initial influx of radicals can be quickly deactivated before termination. Therefore, since PREDICI confirmed that the RT/CRT ratio can be kinetically controlled by changing the initial conditions, a pMA-Br ATRP macroinitiator with 99\% 
chain end functionality (CEF; from ${ }^{1} \mathrm{H}$ NMR, Figure S1) was synthesized via $\mathrm{Ag}^{0} \mathrm{ATRP} .60$ By changing the $R T_{22} / C R T$ ratio, one can analyze the resulting polymer products via SEC to determine the proportion of high MW to low MW polymer and thus obtain invaluable mechanistic information about the products of RT and CRT.

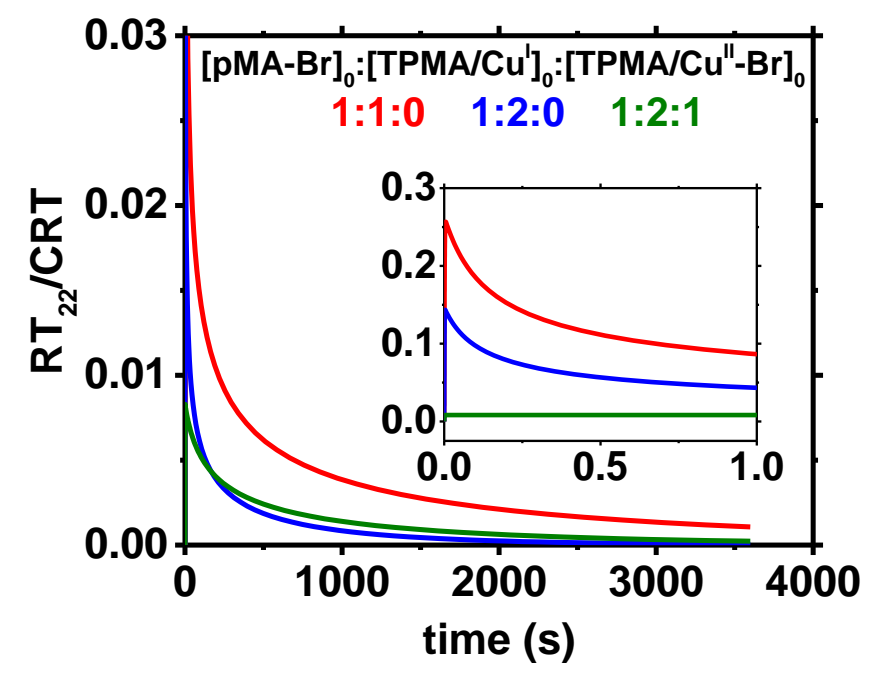

Figure 1. PREDICl simulations of termination of radicals generated from a $\mathrm{pMA}-\mathrm{Br}$ macroinitiator. $\mathrm{RT}_{22} / \mathrm{CRT}$ ratio vs. time under three different initial conditions [pMA$\mathrm{Br}]_{0}:\left[\mathrm{L} / \mathrm{Cu}^{\prime}\right]_{0}:\left[\mathrm{L} / \mathrm{Cu}^{\prime \prime}-\mathrm{Br}\right]_{0}=1: 1: 0$ (red), 1:2:0 (blue) and 1:2:1 (green) where $\mathrm{L}=$ TPMA. The reaction model and rate coefficients used for simulations are presented in Table S2.

In order to reassess previous contributions, experiments were first conducted under conditions similar to those reported by Yamago et al. ${ }^{22}$ In order to eliminate assumptions which were not accounted for by Yamago, we slightly altered the experimental setup. One significant difference is the choice of copper salt and solvent. $\left[\mathrm{Cu}^{\prime}\left(\mathrm{MeCN}_{4}\right]\left[\mathrm{PF}_{6}\right]\right.$ in acetonitrile was used throughout this study, while Yamago et al. used $\mathrm{Cu}^{\prime} \mathrm{Br}$ in toluene. In our study, the use of $\left[\mathrm{Cu}^{\prime}(\mathrm{MeCN})_{4}\right]\left[\mathrm{PF}_{6}\right]$ results in the formation of a discrete $\left[\mathrm{Cu}^{\prime}\left(\mathrm{Me}_{6} \mathrm{TREN}\right)\right]^{+}$catalyst in situ, while the use of $\mathrm{Cu}^{\prime} \mathrm{Br}$ has been shown to form a mixture

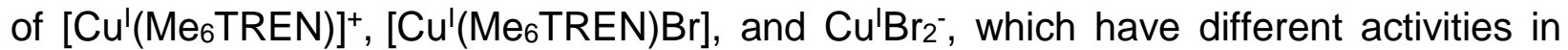
ATRP $^{61}$ and thus could have skewed previously reported conclusions. Secondly, to make sure there was no disproportionation of the $\mathrm{L} / \mathrm{Cu}^{\prime}$ species, $\mathrm{MeCN}$ was chosen as the solvent instead of toluene. Finally, Yamago et al. conducted all but one of their termination experiments in the presence of $\mathrm{Cu}^{0}$ powder, which has recently ${ }^{62}$ been shown to also catalyze the termination of acrylate radicals and would be indistinguishable from 
$\mathrm{Cu}^{\prime} \mathrm{CRT}$. In addition, avoiding the use of $\mathrm{Cu}^{0}$ allows facile monitoring of the extent of termination by the determination of [L/Cu"], since $\mathrm{Cu}^{0}$ is able to comproportionate with $\mathrm{Cu}^{\prime \prime}$ to regenerate $\mathrm{Cu}$ and would not allow for efficient monitoring of [L/Cull].

\section{RESULTS AND DISCUSSION}

\section{Termination in the Presence of $\mathrm{Me}_{6} \mathrm{TREN} / \mathrm{Cu}^{\prime}$ Complex}

Termination experiments were conducted in the absence of monomer and termination extent could be determined from the increase in [L/Cu"l-Br], according to the principle of halogen conservation. ${ }^{63}$ This allowed the amount of termination to be related to the SEC traces of the resulting terminated polymer (Figure 2). Using the same [pMA$\mathrm{Br}]_{0}:\left[\mathrm{Me}_{6} \mathrm{TREN} / \mathrm{Cu}^{\prime}\right]_{0}=1: 5$ as previously reported ${ }^{22}$, a high molecular weight shoulder accounting for $27 \%$ of chains was observed for the polymer recovered after quantitative (>99 \%) termination. This is in very good agreement with the Yamago contribution, where $25 \%$ of chains were reported to have doubled molecular weight. As predicted by Eq $\mathbf{1}$, upon addition of [Me $\left.{ }_{6} \mathrm{TREN} / \mathrm{Cu}^{\mathrm{l}}-\mathrm{Br}\right]^{+}$deactivator, the amount of conventional radical termination was kinetically suppressed relative to CRT. Upon addition of 0.5 or 1 equivalents of [Me $\left.{ }_{6} T R E N / \mathrm{Cu}^{\prime \prime}-\mathrm{Br}\right]^{+}$relative to $[\mathrm{pMA}-\mathrm{Br}]$, the fraction of high molecular weight polymer decreased from $27 \%$ to $9 \%$ and $7 \%$, respectively (in all cases, the termination was quantitative after 1 hour according to the [Me 6 TREN/Cull] analysis). These results would indicate that the high molecular weight peak previously attributed to CRT coupling 22 is actually the result of non-catalyzed termination (RT), due to the high radical concentration triggered by fast $\mathrm{pMA}-\mathrm{Br}$ chain-end activation by the $\left[\mathrm{Cu}^{\prime}\left(\mathrm{Me}_{6} \mathrm{TREN}\right)\right]^{+}$catalyst. 

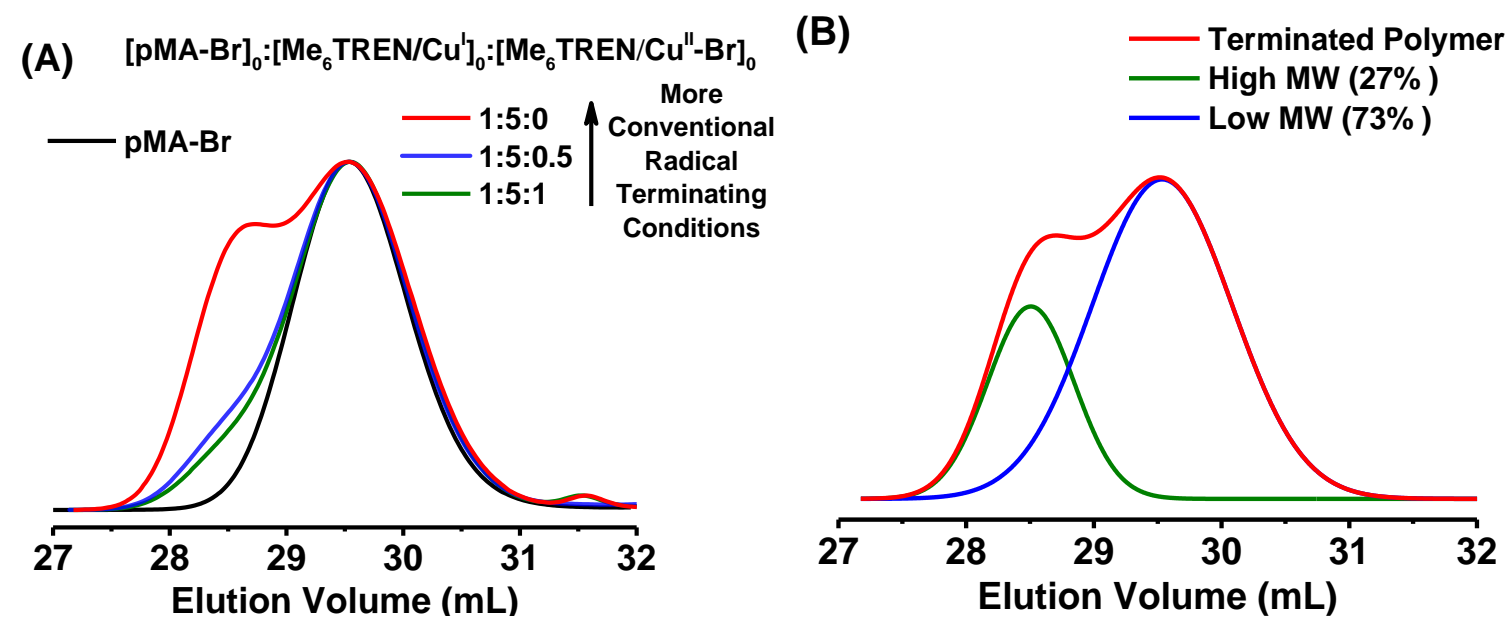

Figure 2 (A) SEC traces of the termination products from the pMA-Br macroinitiator recovered after 30 min at different $R T / C R T$ ratios and $(B)$ deconvolution of the product of reaction [pMA-Br]:[Me 6 TREN/Cu'] = 1:5. Conditions: [pMA$\mathrm{Br}]:\left[\mathrm{Me}_{6} \mathrm{TREN} / \mathrm{Cu}^{\prime}\right]:\left[\mathrm{Me} 6 \mathrm{TREN} / \mathrm{Cu}^{\prime \prime}-\mathrm{Br}\right]=1: 5: 0-1$ in anhydrous $\mathrm{MeCN}$ at room temperature; $[\mathrm{pMA}-\mathrm{Br}]_{0}=1.6 \mathrm{mM}$.

In order to assess the products of RT and CRT under more relevant polymerization conditions, termination reactions under [pMA-Br]0:[Me6 TREN/Cu'] $]_{0}=1: 1-2$ ratios were conducted. The kinetics of termination and the resulting SEC traces of the terminated polymer are presented in Figure 3. Under the initial conditions [pMA$\mathrm{Br}]_{0}:\left[\mathrm{Me}_{6} \mathrm{TREN} / \mathrm{Cu}^{\prime}\right]_{0}=1: 1,81 \%$ of chains were terminated after one hour with $38 \%$ high molecular weight fraction compared to $>99 \%$ and $27 \%$, respectively, when this ratio was 1:5. Upon initial addition of 0.5 eq. of deactivator complex [Me6TREN/Cu" $-\mathrm{Br}]^{+}$relative to [pMA-Br]o and doubling [Me $\left.6{ }_{6} \mathrm{TREN} / \mathrm{Cu}^{\prime}\right]_{0}$, the high molecular weight shoulder decreased to $18 \%$ while achieving $91 \%$ termination. The higher amount of terminated chains is due to the excess of [Me6TREN/Cu']o relative to [pMA-Br]o. The high molecular weight peak was further decreased upon initial addition of 1 eq. of deactivator complex to give only $7 \%$ high molecular weight chains at quantitative termination. These results indicate that acrylate radicals terminate via combination, while CRT gives a terminated polymer with the same molecular weight as the pMA-Br macroinitiator, contrary to recent reports. ${ }^{22,27}$ Due to the high activity of the [Me ${ }_{6} T R E N / C u$ '] activator complex, the initial concentration of radicals could not be suppressed efficiently to completely eliminate RT, as evidenced by the small high molecular weight fraction even in the presence of 1 eq. of deactivator complex. 
(A)

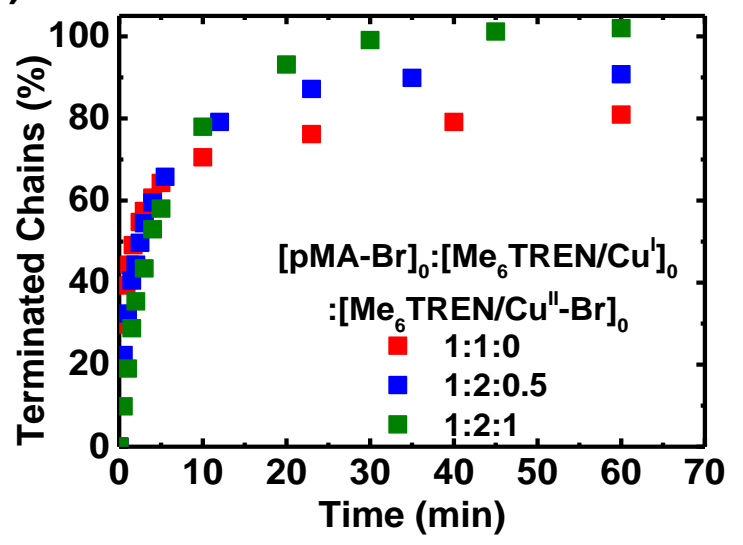

(B) [pMA-Br $]_{0}:\left[\mathrm{Me}_{6} \mathrm{TREN} / \mathrm{Cu}\right]_{0}:\left[\mathrm{Me}_{6} \mathrm{TREN} / \mathrm{Cu} \text { "-Br }\right]_{0}$

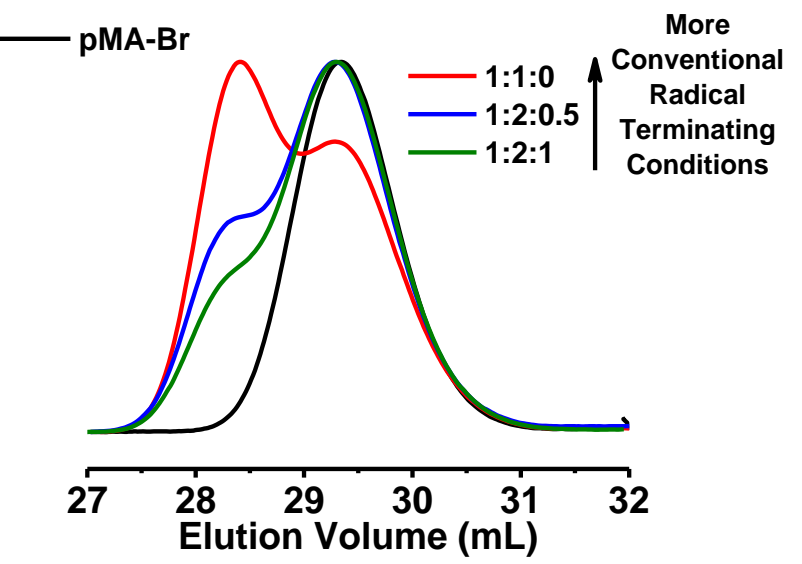

Figure $3(A)$ evolution of fraction of terminated chains with time and (B) SEC traces of the termination product of $\mathrm{pMA}-\mathrm{Br}$ macroinitiator recovered after $30 \mathrm{~min}$ at different RT/CRT ratios. Reaction conditions: [pMA-Br]0:[Me6TREN/Cu']0:[Me6TREN/Cull-Br]0 = 1:1-2:0-1, in anhydrous MeCN at room temperature; [pMA-Br] $=1.6 \mathrm{mM}$.

\section{Termination in the Presence of TPMA/Cu' Complex}

The next termination experiments were carried out using the $\left[\mathrm{Cu}^{\prime}(\mathrm{TPMA})\right]^{+}(\mathrm{TPMA}=$ tris(2-pyridylmethyl)amine)) catalyst as shown in Figure 4. The catalyst was used at two different [pMA-Br]0:[TPMA/Cu']o ratios. With [pMA-Br]o:[TPMA/Cu'] $0=1: 1,67 \%$ of chains were terminated after one hour, but only $7 \%$ of all chains corresponded to the high molecular weight shoulder, compared to $38 \%$ for the Me 6 TREN system under the same conditions. The fraction of high molecular weight terminated polymer was further decreased by decreasing the RT/CRT ratio using different concentration of [TPMA/Cu']o and [TPMA/Cu" $-\mathrm{Br}$ ]. Relative to the Me6TREN system, the lower fraction of doubled molecular weight product is due to the lower ATRP activity of the TPMA catalyst. The rate coefficient of pMA-Br activation is approximately $10 \mathrm{x}$ higher for [ $\left.\mathrm{Cu}^{\prime}\left(\mathrm{Me}_{6} \mathrm{TREN}\right)\right]^{+}$ compared to $\left[\mathrm{Cu}^{\prime}(\mathrm{TPMA})\right]^{+}$. ${ }^{64}$ Since the rate of radical termination is proportional to $[R \cdot]^{2}$ and the rate of CRT is proportional only to [R・], a 10-fold increase in radicals leads to a 100 times faster RT and only 10 times faster CRT. 

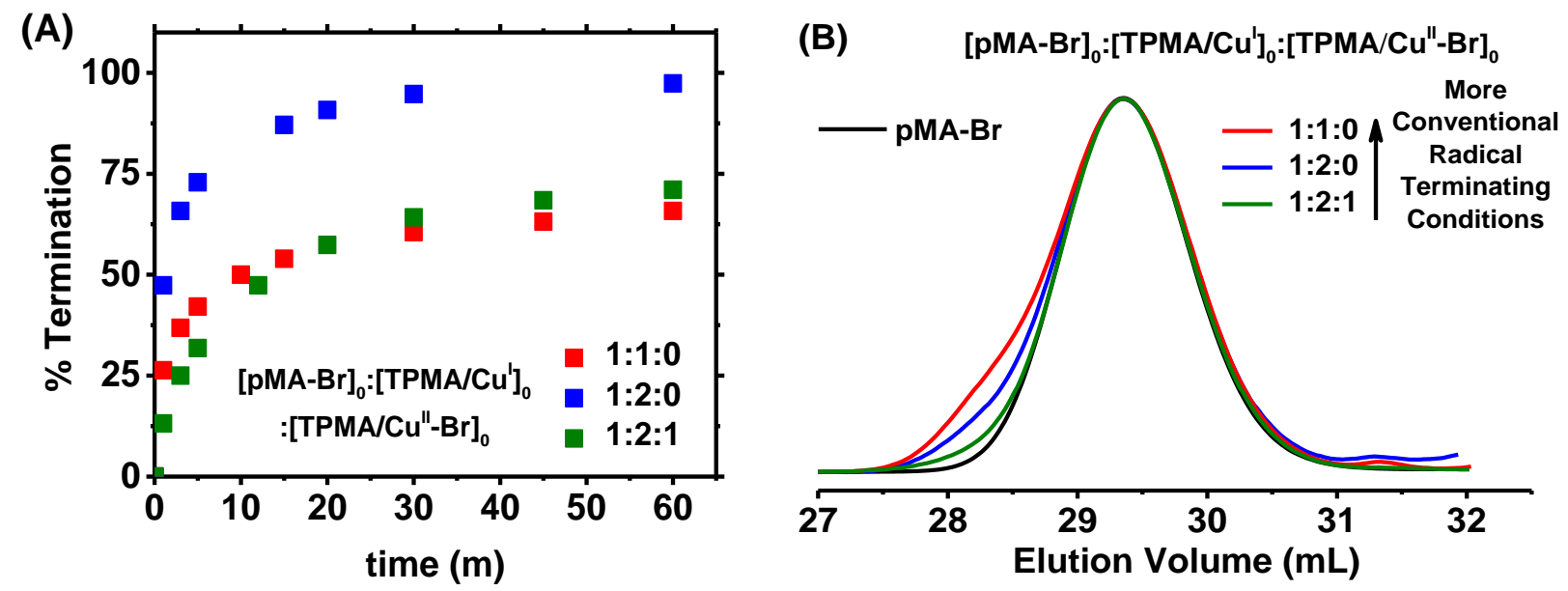

Figure $4(A)$ Evolution of fraction of terminated chains with time and (B) SEC trace of the termination product of pMA-Br macroinitiator recovered after $1 \mathrm{~h}$ at different RT/CRT ratios. Reaction conditions: [pMA-Br]0:[TPMA/Cu']0:[TPMA/Cull-Br]0 $=1: 1-2: 0-1$, in anhydrous $\mathrm{MeCN}$ at room temperature; $[\mathrm{pMA}-\mathrm{Br}]_{0}=2 \mathrm{mM}$.

\section{Termination in the Presence of $\mathrm{Cu}^{\prime} / \mathrm{TPMA}^{* 3}$ Complex}

As noted earlier, the ratio of RT to CRT can be tuned by changing $K_{\text {ATRP }}$ (Eq 1). One way to increase $K_{\text {ATRP }}$ is by using more active L/Cul catalysts. ${ }^{48,65}$ In fact, the use of Me6TREN by Yamago increases KATRP by approximately 10 compared to the TPMA system reported in Figure 3. However, to use geometrically similar pyridinic-based catalysts, $\left[\mathrm{Cu}^{\prime}\left(\mathrm{TPMA}^{\prime}\right)\right]\left[\mathrm{PF}_{6}\right]$ was replaced with the more active $\left[\mathrm{Cu}^{\prime}\left(\mathrm{TPMA}^{* 3}\right)\right]\left[\mathrm{PF}_{6}\right]\left(\mathrm{TPMA}^{* 3}=\right.$ tris(3,5-dimethyl-4-methoxy-2-pyridylmethyl)amine) catalyst, which should also lead to a higher initial concentration of radicals. As alluded to above, this should lead to a faster rate of RT relative to CRT compared to the TPMA system. Therefore, assuming that RT occurs via combination, as suggested by the investigations of the TPMA and Me6TREN systems above, a larger fraction of high molecular weight peak should be observed when using TPMA ${ }^{* 3}$ compared to TPMA under the same conditions.

Indeed, the termination experiment under conditions $[\mathrm{pMA}-\mathrm{Br}]_{0}:\left[\mathrm{TPMA}^{* 3} / \mathrm{Cu}^{\prime}\right]_{0}:=1: 1$ (Figure 5) confirmed this expectation. After only 5 minutes, $98 \%$ of chains were terminated, compared to only $67 \%$ after 1 hour for the TPMA system under the same initial conditions. This is due to the much higher activity of the $\mathrm{TPMA}^{* 3} / \mathrm{Cu}^{\prime}$ catalyst. Deconvolution of the resulting SEC traces showed $24 \%$ of the chains terminated via 
combination for TPMA ${ }^{* 3}$ compared to only $7 \%$ for TPMA. Under the conditions [PMA$\mathrm{Br}]_{0}:\left[\mathrm{TPMA}^{* 3} / \mathrm{Cu}^{\prime}\right]_{0}:=1: 2$ all chains were terminated in only 4 minutes and the high molecular weight shoulder accounted for only $12 \%$ of all chains, indicating a larger fraction of CRT relative to RT. Upon initial addition of 0.5 or 1 equivalent of $T P M A * 3 / \mathrm{Cu}^{11}$ $\mathrm{Br}$ deactivator, the high molecular weight peak decreased to 7 and $4 \%$, respectively, with $>99 \%$ of chains terminated. The concurrent decrease of the high molecular weight shoulder with decreasing RT provides further evidence that RT occurs predominantly via combination while CRT gives products with the same molecular weight as the pMA-Br macroinitiator. Like in the $\mathrm{Me}_{6} \mathrm{TREN}$ system, a small fraction of high molecular weight product was observed due to the high activity of the TPMA*3/Cu' catalyst.
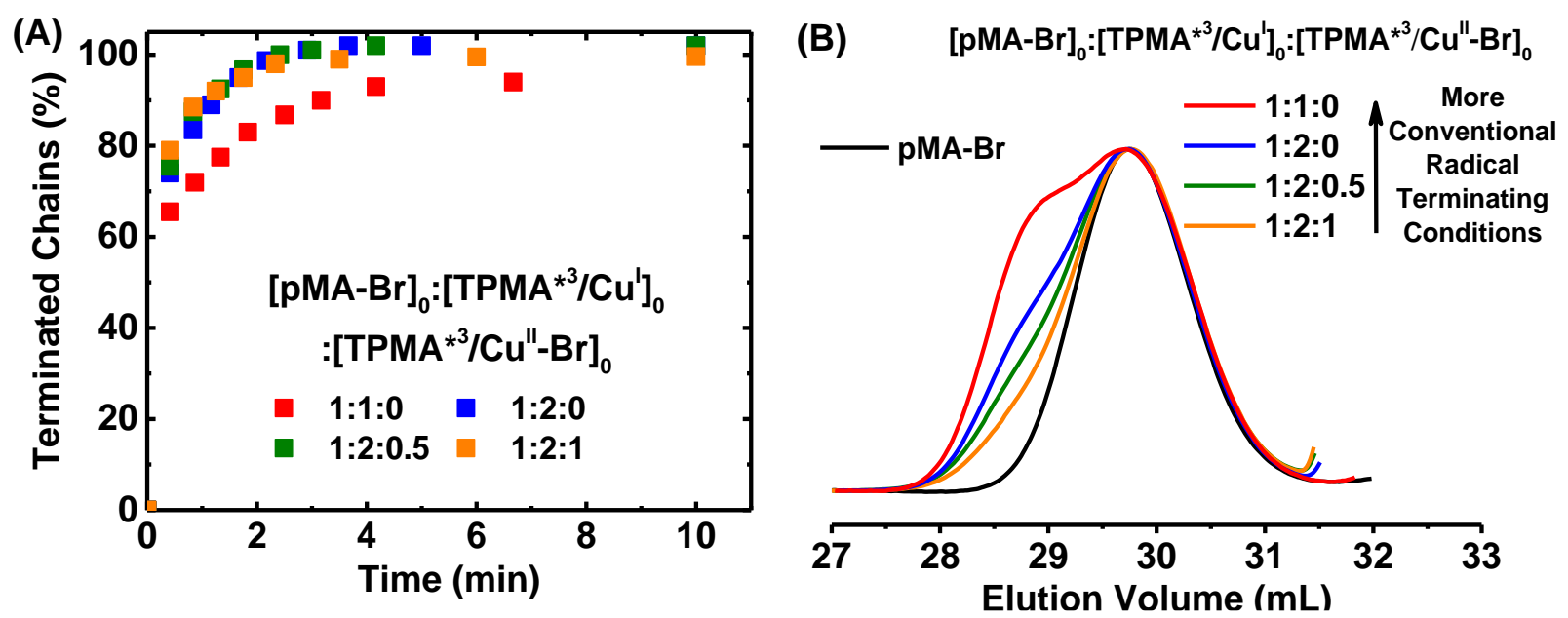

Figure 5 (A) Evolution of fraction of terminated chains with time and (B) SEC traces of the termination product of pMA-Br macroinitiator recovered after $1 \mathrm{~h}$ at different RT/CRT ratios. Reaction conditions: [pMA-Br]0:[TPMA*3/Cu']0:[TPMA*3/Cull-Br]0 = 1:1-2:0-1, in anhydrous $\mathrm{MeCN}$ at room temperature; $[\mathrm{pMA}-\mathrm{Br}]_{0}=2.5 \mathrm{mM}$ ).

An interesting question arises as to why the TPMA $^{\star 3}$ system did not show as much of a high molecular weight peak as the Me6TREN system. This is most likely due to much faster association of the pMA radicals to $\mathrm{TPMA}^{* 3} / \mathrm{Cu}^{\prime}$ relative to $\mathrm{Me}_{6} \mathrm{TREN} / \mathrm{Cu}$ '. In fact, UV-Vis analysis shows the formation of both the TPMA*3/Cu"l-Br and the TPMA*3/CullpMA organometallic species (Figure S5). Since this organometallic species was observed on the time scale of the reaction, this means that TPMA*3/Cu"-pMA is more thermodynamically stable (larger value of KOMRP) ${ }^{58}$ than Me 6 TREN/Cull-pMA. Formation 


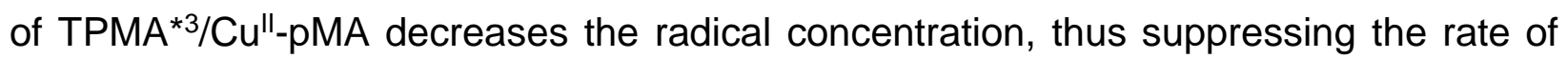
bimolecular termination and therefore decreasing the fraction of high molecular weight product in SEC.

The summary of all termination reactions (Table 1 ) clearly shows that the RT/CRT ratio can be kinetically altered by changing the [pMA-Br]:[L/Cu']:[L/Cu"l-Br] ratios but also by changing $K_{\text {ATRP. }}$. As the RT/CRT ratio was kinetically decreased, the relative fraction of high molecular polymer (Comb/Disp) also decreased. These results indicate that bimolecular radical termination of acrylates operates predominantly via combination while CRT gives predominantly chains with the same molecular weight as the pMA-Br initiator.

Table 1 Experimental product distribution of the termination reactions.

\begin{tabular}{|c|cccccc|}
\hline Ligand & $\begin{array}{c}\text { [pMA-Br]: } \\
{\left[\begin{array}{c}\text { [L/Cu']:[L/Cu"- } \\
\mathbf{B r}]\end{array}\right.}\end{array}$ & $\begin{array}{c}\text { Terminated } \\
(\%)^{\mathbf{a}}\end{array}$ & $\begin{array}{c}\text { Living } \\
(\%)\end{array}$ & $\begin{array}{c}\text { Combined } \\
(\%)^{\mathbf{b}}\end{array}$ & $\begin{array}{c}\text { Disp } \\
(\%)^{\mathbf{c}}\end{array}$ & $\begin{array}{c}\% \text { Disp. Of } \\
\text { All Term }^{\mathbf{d}}\end{array}$ \\
\hline \multirow{4}{*}{ Me6TREN } & $1: 1: 0$ & 81 & 19 & 38 & 43 & 53 \\
& $1: 2: 0.5$ & 91 & 9 & 18 & 73 & 80 \\
& $1: 2: 1$ & $>99$ & $<1$ & 13 & 86 & 86 \\
& $1: 5: 0$ & $>99$ & $<1$ & 27 & 73 & 73 \\
& $1: 5: 0.5$ & $>99$ & $<1$ & 9 & 91 & 91 \\
& $1: 5: 1$ & $>99$ & $<1$ & 7 & 93 & 93 \\
\hline \multirow{3}{*}{ TPMA $^{*}$} & $1: 1: 0$ & 67 & 33 & 7 & 60 & 90 \\
& $1: 2: 0$ & 98 & 2 & 5 & 93 & 95 \\
& $1: 2: 1$ & 71 & 29 & 2 & 69 & 97 \\
\hline \multirow{3}{*}{ TPMA $^{* 3}$} & $1: 1: 0$ & 98 & 2 & 24 & 74 & 76 \\
& $1: 2: 0$ & $>99$ & $<1$ & 12 & 88 & 88 \\
& $1: 2: 0.5$ & $>99$ & $<1$ & 7 & 93 & 93 \\
& $1: 2: 1$ & $>99$ & $<1$ & 4 & 96 & 96 \\
\hline
\end{tabular}

All percentages were calculated at $t=30 \mathrm{~min}\left(\mathrm{TPMA}^{* 3}\right)$ or $1 \mathrm{~h}$ (TPMA and $\mathrm{Me}_{6}$ TREN); Relative to [pMA-Br]o unless otherwise noted. a Calculated based on the increase of [L/Cull-Br]; ${ }^{b}$ The High MW from the deconvoluted SEC traces; ${ }^{\circ}$ Calculated from the Low MW fraction of the deconvoluted SEC traces as Low MW = Living + Disp; ${ }^{d}$ Calculated as the amount of chains terminated by disproportionation related to all terminated chains. 
To further quantify the termination reactions, PREDICI simulations were conducted. In order to obtain useful mechanistic information, the kinetic model in use must first be validated by comparing to experimental results. In this case, experimental [ $\mathrm{L} / \mathrm{Cu}$ "-Br] was conveniently monitored by UV-Vis spectroscopy and then compared to the PREDICI simulations.

One major area of debate in the termination of acrylate radicals is the extent of backbiting for which reported rate coefficients, $k_{b b}$, span 4 orders of magnitude at the same temperature. ${ }^{38}$ However, backbiting is an important feature of acrylate polymerization and cannot be neglected. ${ }^{32}$ In fact, setting $k_{b b}=0$ in the simulation (Figure 6A) caused a significant underestimation of the experimental [L/Cull-Br]. Therefore, backbiting was included in the simulation, taking into account the most recent and accurate $k_{b b}$ value at room temperature reported by Buback et al. ${ }^{16,33}$ using the PLP-SEC or PLP-EPR methods $\left(40<k_{b b}<250\right)$ and Asua et a ${ }^{38}$ using experimental fitting $(10<$ $\left.k_{b b}<40\right)$ also at room temperature. With $k_{b b}$ in this range, all simulations agreed better with the experimental data, and the best agreement was obtained for $k_{b b}=40 \mathrm{~s}^{-1}$ at room temperature. It should be noted that the value of $k_{b b}$, within its interval of accuracy, was the only value fitted to the experimental data, whereas all other values were taken directly from the literature or measured in this study (see Supporting Information).
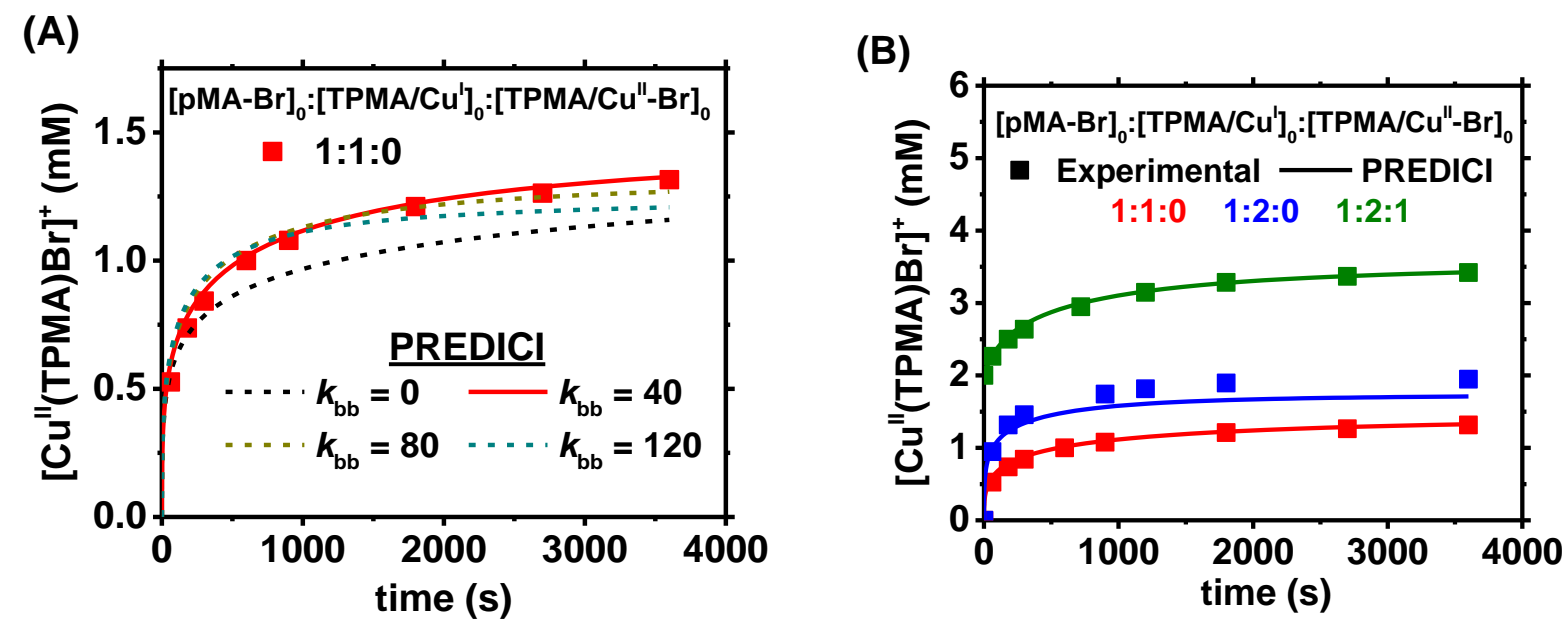


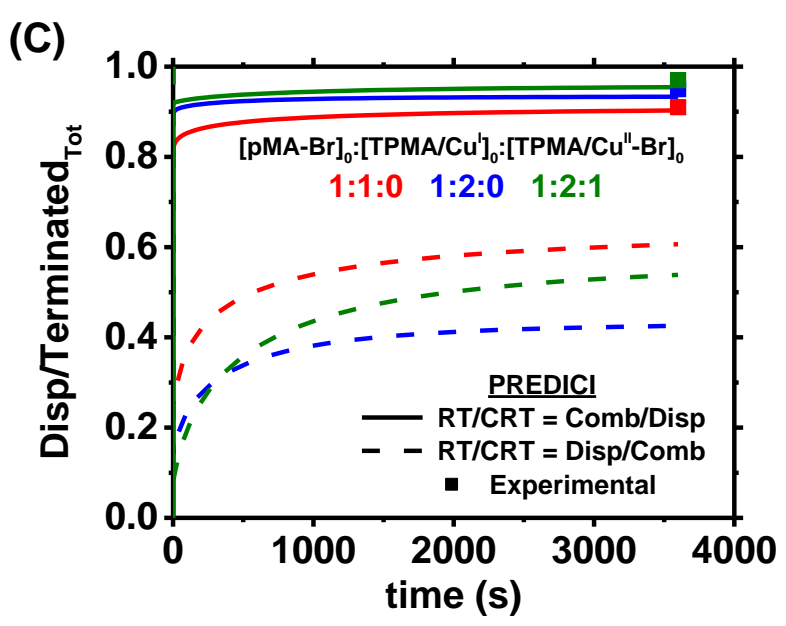

Figure 6 A) Evolution of [TPMA/Cu"l-Br] vs. time for different values of $k_{b b}\left(\right.$ in s $\left.{ }^{-1}\right)$; B) experimental (squares) and simulated (lines) evolution of TPMA/Cu"-Br vs. time; C) fraction of chains terminated by disproportionation relative to total terminated chains for two cases, where RT and CRT give combination and disproportionation, respectively (bold lines) and vice versa (dashed lines). All squares are experimental data obtained either via UV-Vis or SEC under the specified initial ratio with [pMA-Br] $=2 \mathrm{mM}$ in anhydrous $\mathrm{MeCN}$ at room temperature.

The remaining simulations were conducted using the value of $k \mathrm{bb}=40 \mathrm{~s}^{-1}$. As shown in Figure $6 \mathrm{~B}$, the fit between the experimental and simulated evolution of TPMA/Cu" $-\mathrm{Br}$ for the other two $[\mathrm{pMA}-\mathrm{Br}]:\left[\mathrm{L} / \mathrm{Cu}^{\prime \prime}-\mathrm{Br}\right]$ ratios remained good, validating this PREDICI model. Figure $6 \mathrm{C}$ shows the fraction of disproportionated chains to total terminated chains vs. time under two different scenarios. In the bold lines, it was assumed that termination between two chain-end radicals ( $R T_{22}$ ) gives 100\% Comb while CRT gives 100\% Disp. On the other hand, in the dashed lines, the assumptions were reversed, in which case $\mathrm{RT}_{22}$ gives $100 \%$ disproportionation and CRT gives $100 \%$ combination, as has been proposed by Yamago. ${ }^{22,27}$

The extent of Disp/Comb for the mid-chain radical is not precisely known and has only been taken as the average of $\mathrm{RT}_{22}$ and $\mathrm{RT}_{33 .}{ }^{66}$ In light of this and due to the best fitting between experimental and PREDICl, it was assumed that any termination involving tertiary mid-chain radicals ( $\mathrm{RT}_{23}$ and $\mathrm{RT}_{33}$ ) gives $100 \%$ disproportionation. ${ }^{36,} 38$ In fact, Asua et $a^{\beta 0}$ has proposed that the study conducted by Yamago et a/27 more accurately models how tertiary mid-chain radicals terminate as opposed to chain-end radicals due 
to $\left[\mathrm{P}_{3^{\bullet}}\right]>\left[\mathrm{P}_{2}{ }^{\bullet}\right]$. This gives further support of bimolecular termination involving mid-chain radicals terminating by disproportionation at room temperature. The experimental results can only be explained if one assumes that $R T_{22}$ operates via combination while $C R T$ gives products of disproportionation. This further validates the experiments conducted above, in which reactions that were kinetically tuned to promote RT vs. CRT gave a higher molecular weight shoulder.

To quantify the contribution of each reaction toward the decrease in chain-end functionality, the evolution of all products of termination were simulated with respect to time. In the present model, there are four pathways in which radicals can terminate: 1 ) CRT, the reaction between TPMA/Cull- $\mathrm{P}_{2}$ and a chain-end radical, $\mathrm{P}_{2} ; 2$ ) $\mathrm{RT}_{22}$, the reaction between two chain-end radicals; 3) $\mathrm{RT}_{23}$, the "cross-termination" between a chain-end radical and a mid-chain radical; 4) $R T_{33}$, the reaction between two mid-chain radicals. Based on the good fit between experimental and simulations in Figure $6 \mathrm{C}$, the three reactions $C R T, R_{23}$ and $R T_{33}$ were simulated to give disproportionated chains and $\mathrm{RT}_{22}$ was set to give combined chains. Figure 7 shows the distribution of products obtained by these four termination reactions. 
(A)

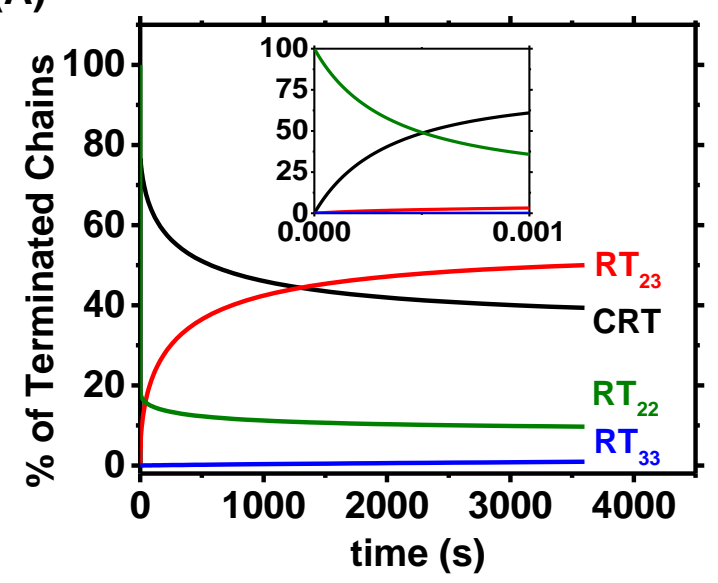

(B)

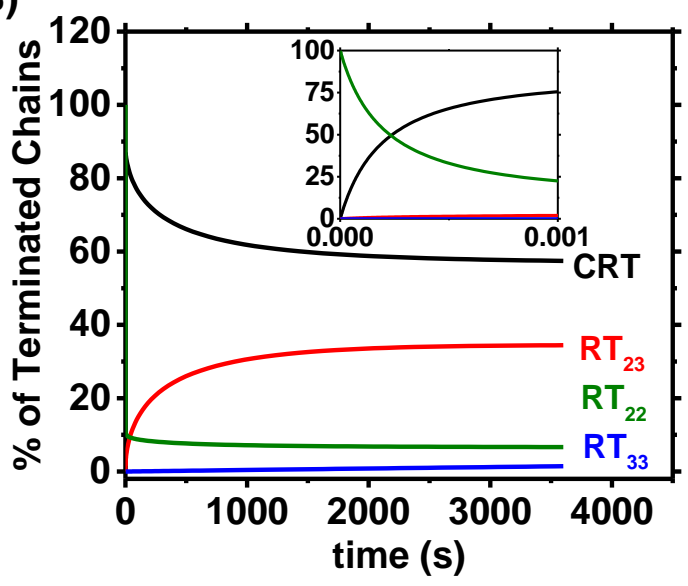

(C)

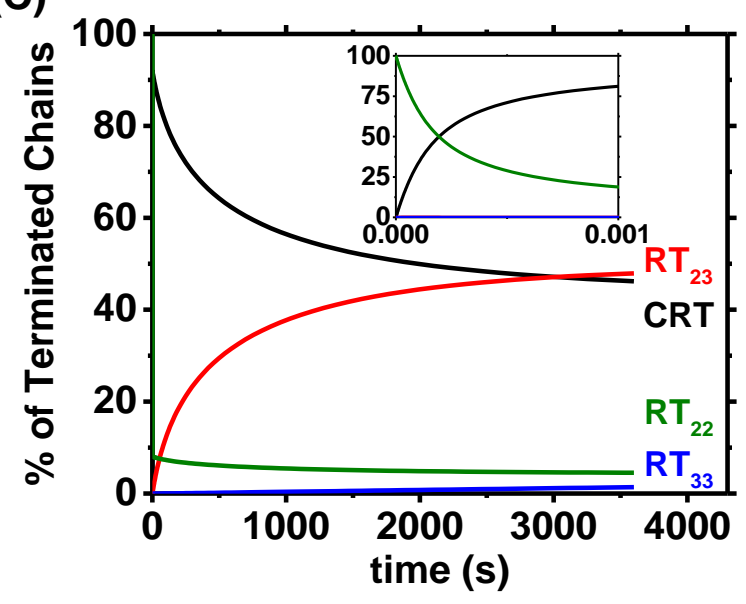

Figure 7 Simulations of the contribution of CRT (black), $\mathrm{RT}_{23}$ (red), $\mathrm{RT}_{22}$ (green) and $\mathrm{RT}_{33}$ (blue) to total termination vs. time under the initial [pMA-Br]o:[TPMA/Cu']o:

[TPMA/Cull-Br] ratios of (A) 1:1:0 (B) 1:2:0 and (C) 1:2:1 at room temperature. The reaction model and rate coefficients used for simulations are presented in Table S2.

For the ratio $[\mathrm{pMA}-\mathrm{Br}]_{0}:\left[\mathrm{TPMA} / \mathrm{Cu}^{\prime}\right]_{0}:\left[\mathrm{TPMA} / \mathrm{Cu} \mathrm{u}^{\prime \prime}-\mathrm{Br}\right]_{0}=1: 1: 0$ (Figure $7 \mathrm{~A}$ ), a surprising result is the dominance of the bimolecular "cross termination" between chain-end and mid-chain radicals $\left(R T_{23}\right)$. So much, in fact, that after approximately 25 minutes, the majority of terminated chains underwent termination via cross termination. The reasoning becomes apparent when looking at Figure S5B which shows that the concentration of tertiary mid-chain radicals $\left(\mathrm{P}_{3}{ }^{\circ}\right)$ was greater than that of secondary chain-end radicals $\left(\mathrm{P}_{2}{ }^{\circ}\right)$ after only 5 minutes. This relatively higher concentration of mid-chain radicals results from the fast rate of backbiting (BB) as shown in Figure S5D. In fact, backbiting was between 10 and 100 times faster than $\mathrm{RT}_{22}$ due to the unimolecular nature of the reaction. 
The high abundance of mid-chain radicals in acrylate polymerization has previously been observed via EPR even at room temperature. ${ }^{32}$ PREDICI simulations showed that after one hour, $50 \%$ of all terminated chains were terminated via $\mathrm{RT}_{23}$ while surprisingly only $39 \%$ were terminated via CRT. Only within the first millisecond of the reaction, when $\left[\mathrm{P}_{2}{ }^{\circ}\right]$ was highest (Figure S5A), did $R T_{22}$ dominate $R T_{23}$, as shown in the insert in Figure 7A. Finally, due to the slower reaction between two sterically hindered mid-chain radicals, $\mathrm{RT}_{33}$ accounted for only $1 \%$ of all terminated chains.

The simulations under the more CRT promoting conditions of [pMA$\mathrm{Br}]_{0}:\left[\mathrm{TPMA} / \mathrm{Cu}^{\prime}\right]_{0}:\left[\mathrm{TPMA} / \mathrm{Cu}^{\prime \prime}-\mathrm{Br}\right]_{0}=1: 2: 0$ were similar to those using the 1:1:0 ratio, since the initial ratio of RT and CRT rates does not depend on [TPMA/Cull-Br]o (Equation 1). However, relatively more chains were terminated via CRT. This is due to a two-fold effect of the excess TPMA/Cul on the overall rate of termination. Firstly, the faster $\mathrm{P}_{2}{ }^{\cdot}$ trapping by TPMA $/ \mathrm{Cu}^{\prime}$ suppressed chain-end radical concentration thus slowing down the backbiting reaction (Figure S6) and suppressing the rate of cross-termination, $\mathrm{RT}_{23}$, by an order of magnitude. Secondly, this caused a slight initial increase in [TPMA/Cu"l-P], which resulted in a faster increase of the CRT rate as shown in Figure S6D. Under these initial conditions, CRT accounted for $57 \%$ of all terminated chains compared to $39 \%$ for the $1: 1: 0$ ratio. Furthermore, at this $1: 2: 0$ ratio, $7 \%$ of chains were terminated via $R_{22}$ compared to $10 \%$ under the 1:1:0 ratio, as expected according to Figure 1. Nonetheless, $\mathrm{RT}_{23}$ still dominated all bimolecular radical-based termination events, accounting for $34 \%$ of all terminated chains.

Using the initial ratio [pMA-Br]0:[TPMA/Cu'] $]_{0}\left[\mathrm{TPMA} / \mathrm{Cu}{ }^{\prime \prime}-\mathrm{Br}\right]_{0}=1: 2: 1$, only $4 \%$ of chains were terminated via $\mathrm{RT}_{22}$. This is because the concentration of chain-end radicals was significantly suppressed by the quick and efficient trapping by the TPMA/Cu" $-\mathrm{Br}$ deactivator present from the beginning. As shown in Figure S7C, after one second, the concentration of chain-end radicals was $\left[\mathrm{P}_{2}{ }^{\circ}\right] \approx 7 \times 10^{-8} \mathrm{M}$ in the presence of the deactivator. In comparison, after one second but in the absence of initially added deactivator, $\left[\mathrm{P}_{2}{ }^{\circ}\right] \approx 3 \times 10^{-7} \mathrm{M}$ as shown in Figure S6A. Interestingly, the amount of CRT and $\mathrm{RT}_{23}$ were $46 \%$ and $48 \%$, respectively. Under these "most CRT promoting 
conditions," one would have expected the most amount of CRT according to Eq 1. This can be rationalized on the basis that the initial rate of CRT is suppressed by a factor of 50 due to the suppression of $\left[\mathrm{P}_{2}{ }^{\circ}\right]$ by the initially added TPMA/Cu"l- $\mathrm{Br}$ deactivator. Since CRT requires the reaction between TPMA/CuII- $\mathrm{P}_{2}$ and $\left[\mathrm{P}_{2}{ }^{\circ}\right]$, the suppression of the latter will undoubtedly slow down the rate of CRT. Although the "most CRT-promoting conditions" did in fact lead to the most amount of disproportionation, they did not result in the most amount of chains being terminated via CRT. Thus, Eq 1 would be better referenced as a way to kinetically suppress $R_{22}$ as opposed to kinetically promote CRT. The summary of the distribution of terminated polymer according to our simulations are summarized in Table 2.

It should be noted that in the case of a polymerization reaction, the mid-chain radicals can also add to acrylate monomer leading to a branching point and regenerate the secondary chain-end radical. This could significantly decrease the concentration of midchain radicals and increase the concentration of chain-end radicals compared to this study. This would presumably decrease the contribution of $R T_{23}$ and $R T_{33}$ while increasing the contribution of $\mathrm{RT}_{22}$ and CRT. Nonetheless, in "termination reactions" the lack of monomer allows for a build-up of MCRs and thus bimolecular radical termination involving MCRs cannot be neglected.

Table 2 Product distribution of terminated polymer chains.

\begin{tabular}{|c|cccc|}
\hline $\begin{array}{c}\text { [pMA-Br]: } \\
\text { [L/Cu']:[L/Cu'l-Br] }\end{array}$ & $\begin{array}{c}\text { CRT } \\
(\%)\end{array}$ & $\begin{array}{c}\mathbf{R T}_{23} \\
(\%)\end{array}$ & $\begin{array}{c}\mathbf{R T}_{33} \\
(\%)\end{array}$ & $\begin{array}{c}\mathbf{R T}_{22} \\
(\%)\end{array}$ \\
\hline $1: 1: 0$ & 39 & 50 & 1 & 10 \\
$1: 2: 0$ & 57 & 34 & 2 & 7 \\
$1: 2: 1$ & 46 & 48 & 2 & 4 \\
\hline
\end{tabular}

All percentages were calculated based on total terminated chains Termtot= $[\mathrm{CRT}]+\left[\mathrm{RT}_{23}\right]+\left[\mathrm{RT}_{33}\right]+2 *\left[\mathrm{RT}_{22}\right]$ since chains undergoing combination comprise two initial pMA-Br macroinitiators. For all cases $L=T P M A$.

The results presented here indicate that $R T_{22}$ operates predominately via combination whereas CRT gives products with the same molecular weight as the living chain. This is in direct contrast to the previous contribution by Yamago et al., which concluded that 
acrylate chain-end termination occurs predominately (>99\%) via disproportionation ${ }^{27}$ while CRT gives coupling. ${ }^{22}$ In order to rationalize the results observed with the organotellurium systems studied by Yamago, we have disclosed $\cdot$ TeR radical catalyzed disproportionation via an $\mathrm{H}-\mathrm{TeR}$ intermediate. ${ }^{29}$ Due to the incorrect assumption that acrylate radicals terminate exclusively via disproportionation at room temperature, it seems that Yamago et al have erroneously assigned the formation of the observed combination products to copper catalyzed termination. The high molecular weight in that study ${ }^{22}$ is actually the result of conventional radical termination via combination.

\section{CONCLUSIONS}

Termination reactions using a pMA-Br ATRP macroinitiator were utilized to shed light on the termination mechanism of polyacrylates in ATRP. Three different catalysts were used under various conditions to change the fraction of bimolecular chain-end radical termination (RT) to copper-catalyzed radical termination (CRT). Wherever the RT/CRT ratio was largest, a high molecular weight shoulder became apparent in the SEC traces. As this ratio was gradually decreased, the relative fraction of high molecular weight polymer decreased significantly. This indicates that the bimolecular radical termination

of acrylates operates via combination while CRT gives terminated polymers of unchanged molecular weight. These results are in stark contrast to recent reports; therefore, PREDICI simulations were conducted to support our experimental findings. In fact, very similar results were observed for the experimental and simulated data for the TPMAbased system. It was found that due to the high initial radical concentration, bimolecular termination dominated only at the very first instants. After this initial influx of radicals, catalytic radical termination and backbiting dominated the fate of the secondary chainend radical. Due to the relatively high concentration of mid-chain radicals relative to chain-end radicals, the amount of cross termination between mid-chain and chain-end radicals $\left(R T_{23}\right)$ was found to be more dominant than termination via two chain-ends $\left(R T_{22}\right)$ and, in some cases, even more kinetically significant than CRT.

\section{AUTHOR INFORMATION}




\section{Corresponding Authors:}

*(R.P.) Email: rinaldo.poli@lcc-toulouse.fr

*(K.M.) Email: km3b@andrew.cmu.edu

\section{Notes}

The authors declare no competing financial interest.

\section{ACKNOWLEDGEMENTS}

Support from the NSF (CHE 1707490) is acknowledged. We thank the Centre National de la Recherche Scientifique (CNRS) for support through the PICS06782 grant and through the Laboratoire International Associé (LIA) "Laboratory of Coordination Chemistry for Controlled Radical Polymerization". We are also grateful to the French Embassy in Washington D.C. for a Chateaubriand Fellowship to T.R. P.K. acknowledges Dr. Konrad M. Weis Fellowship in Chemistry. Finally we would like to acknowledge Prof. Michael Buback for fruitful discussion and seminal ideas for this work.

\section{REFERENCES}

1. Nicolas, J.; Guillaneuf, Y.; Lefay, C.; Bertin, D.; Gigmes, D.; Charleux, B., Nitroxidemediated polymerization. Progress in Polymer Science 2013, 38 (1), 63-235.

2. Moad, G.; Rizzardo, E.; Thang, S. H., Living Radical Polymerization by the RAFT Process. Australian Journal of Chemistry 2005, 58 (6), 379-410.

3. Matyjaszewski, K., Atom Transfer Radical Polymerization (ATRP): Current Status and Future Perspectives. Macromolecules (Washington, DC, United States) 2012, 45 (10), 4015-4039. 4. Matyjaszewski, K.; Xia, J., Atom Transfer Radical Polymerization. Chemical Reviews 2001, 101 (9), 2921-2990.

5. Matyjaszewski, K.; Tsarevsky, N. V., Macromolecular Engineering by Atom Transfer Radical Polymerization. Journal of the American Chemical Society 2014, 136 (18), 6513-6533.

6. Krys, P.; Matyjaszewski, K., Kinetics of Atom Transfer Radical Polymerization. European Polymer Journal 2017, 89, 482-523.

7. Barner-Kowollik, C.; Buback, M.; Egorov, M.; Fukuda, T.; Goto, A.; Olaj, O. F.; Russell, G. T.; Vana, P.; Yamada, B.; Zetterlund, P. B., Critically evaluated termination rate coefficients for free-radical polymerization: Experimental methods. Progress in Polymer Science 2005, 30 (6), 605-643.

8. Moad, G.; Solomon, D. H., 1 - Introduction. In The Chemistry of Radical Polymerization (Second Edition), Elsevier Science Ltd: Amsterdam, 2005; pp 1-9.

9. Buback, M.; Egorov, M.; Gilbert, R. G.; Kaminsky, V.; Olaj, O. F.; Russell, G. T.; Vana, P.; Zifferer, G., Critically Evaluated Termination Rate Coefficients for Free-Radical Polymerization, 1. The Current Situation. Macromolecular Chemistry and Physics 2002, 203 (18), 2570-2582. 
10. Beuermann, S.; Buback, M.; Davis, T. P.; García, N.; Gilbert, R. G.; Hutchinson, R. A.; Kajiwara, A.; Kamachi, M.; Lacík, I.; Russell, G. T., Critically Evaluated Rate Coefficients for FreeRadical Polymerization, 4. Macromolecular Chemistry and Physics 2003, 204 (10), 1338-1350.

11. Beuermann, S.; Buback, M.; Davis, T. P.; Gilbert, R. G.; Hutchinson, R. A.; Olaj, O. F.; Russell, G. T.; Schweer, J.; van Herk, A. M., Critically evaluated rate coefficients for free-radical polymerization, 2.. Propagation rate coefficients for methyl methacrylate. Macromolecular Chemistry and Physics 1997, 198 (5), 1545-1560.

12. Fantin, M.; Isse, A. A.; Matyjaszewski, K.; Gennaro, A., ATRP in Water: Kinetic Analysis of Active and Super-Active Catalysts for Enhanced Polymerization Control. Macromolecules 2017, 50 (7), 2696-2705.

13. Tang, W.; Matyjaszewski, K., Effect of Ligand Structure on Activation Rate Constants in ATRP. Macromolecules 2006, 39 (15), 4953-4959.

14. Kattner, H.; Buback, M., Detailed Investigations into Radical Polymerization Kinetics by Highly Time-Resolved SP-PLP-EPR. Macromolecular Symposia 2013, 333 (1, Polymer Reaction Engineering), 11-23.

15. Buback, M.; Schroeder, H.; Kattner, H., Detailed Kinetic and Mechanistic Insight into Radical Polymerization by Spectroscopic Techniques. Macromolecules 2016, 49 (9), 3193-3213.

16. Barth, J.; Buback, M., SP-PLP-EPR-A Novel Method for Detailed Studies into the Termination Kinetics of Radical Polymerization. Macromolecular Reaction Engineering 2010, 4 (5), 288-301.

17. Buback, M.; Egorov, M.; Junkers, T.; Panchenko, E., Free-Radical Termination Kinetics Studied Using a Novel SP-PLP-ESR Technique. Macromolecular Rapid Communications 2004, 25 (10), 1004-1009.

18. Olaj, O. F.; Bitai, I.; Hinkelmann, F., The laser-flash-initiated polymerization as a tool of evaluating (individual) kinetic constants of free-radical polymerization, 2. The direct determination of the rate of constant of chain propagation. Die Makromolekulare Chemie 1987, 188 (7), 1689-1702.

19. Buback, M.; Gilbert, R. G.; Russell, G. T.; Hill, D. J. T.; Moad, G.; O'Driscoll, K. F.; Shen, J.; Winnik, M. A., Consistent values of rate parameters in free radical polymerization systems. II. Outstanding dilemmas and recommendations. Journal of Polymer Science Part A: Polymer Chemistry 1992, 30 (5), 851-863.

20. Beuermann, S.; Buback, M., Rate coefficients of free-radical polymerization deduced from pulsed laser experiments. Progress in Polymer Science 2002, 27 (2), 191-254.

21. Bamford, C. H.; Jenkins, A. D., Termination Reaction in Vinyl Polymerization: Preparation of Block Copolymers. Nature 1955, 176 (4471), 78-78.

22. Nakamura, Y.; Ogihara, T.; Yamago, S., Mechanism of $\mathrm{Cu}(\mathrm{I}) / \mathrm{Cu}(0)$-Mediated Reductive Coupling Reactions of Bromine-Terminated Polyacrylates, Polymethacrylates, and Polystyrene. ACS Macro Letters 2016, 5 (2), 248-252.

23. Bamford, C. H.; Dyson, R. W.; Eastmond, G. C., Network formation IV. The nature of the termination reaction in free-radical polymerization. Polymer 1969, 10, 885-899.

24. Buback, M.; Günzler, F.; Russell, G. T.; Vana, P., Determination of the Mode of Termination in Radical Polymerization via Mass Spectrometry. Macromolecules 2009, 42 (3), 652-662.

25. Ayrey, G.; Humphrey, M. J.; Poller, R. C., Radiochemical studies of free-radical vinyl polymerizations: 7. Polymerization of methyl acrylate. Polymer 1977, 18 (8), 840-844. 
26. Szablan, Z.; Junkers, T.; Koo, S. P. S.; Lovestead, T. M.; Davis, T. P.; Stenzel, M. H.; BarnerKowollik, C., Mapping Photolysis Product Radical Reactivities via Soft Ionization Mass Spectrometry in Acrylate, Methacrylate, and Itaconate Systems. Macromolecules 2007, 40 (19), 6820-6833.

27. Nakamura, Y.; Lee, R.; Coote, M. L.; Yamago, S., Termination Mechanism of the Radical Polymerization of Acrylates. Macromolecular Rapid Communications 2016, 37 (6), 506-513.

28. Nakamura, Y.; Ogihara, T.; Hatano, S.; Abe, M.; Yamago, S., Control of the Termination Mechanism in Radical Polymerization by Viscosity: Selective Disproportionation in Viscous Media. Chemistry - A European Journal 2017, 23 (6), 1299-1305.

29. Ribelli, T. G.; Rahaman, W.; Matyjaszewski, K.; Poli, R., Catalyzed Radical Termination in the Presence of Tellanyl Radicals. Chemistry - A European Journal, ASAP.

30. Ballard, N.; Hamzehlou, S.; Ruipérez, F.; Asua, J. M., On the Termination Mechanism in the Radical Polymerization of Acrylates. Macromolecular Rapid Communications 2016, 37 (16), 13641368.

31. Plessis, C.; Arzamendi, G.; Leiza, J. R.; Schoonbrood, H. A. S.; Charmot, D.; Asua, J. M., Modeling of Seeded Semibatch Emulsion Polymerization of n-BA. Industrial \& Engineering Chemistry Research 2001, 40 (18), 3883-3894.

32. Buback, M.; Hesse, P.; Junkers, T.; Sergeeva, T.; Theis, T., PLP Labeling in ESR Spectroscopic Analysis of Secondary and Tertiary Acrylate Propagating Radicals. Macromolecules 2008, 41 (2), 288-291.

33. Nikitin, A. N.; Hutchinson, R. A.; Buback, M.; Hesse, P., Determination of Intramolecular Chain Transfer and Midchain Radical Propagation Rate Coefficients for Butyl Acrylate by Pulsed Laser Polymerization. Macromolecules 2007, 40 (24), 8631-8641.

34. Yu-Su, S. Y.; Sun, F. C.; Sheiko, S. S.; Konkolewicz, D.; Lee, H.-i.; Matyjaszewski, K., Molecular Imaging and Analysis of Branching Topology in Polyacrylates by Atomic Force Microscopy. Macromolecules 2011, 44 (15), 5928-5936.

35. Ahmad, N. M.; Charleux, B.; Farcet, C.; Ferguson, C. J.; Gaynor, S. G.; Hawkett, B. S.; Heatley, F.; Klumperman, B.; Konkolewicz, D.; Lovell, P. A.; Matyjaszewski, K.; Venkatesh, R., Chain Transfer to Polymer and Branching in Controlled Radical Polymerizations of n-Butyl Acrylate. Macromolecular Rapid Communications 2009, 30 (23), 2002-2021.

36. Konkolewicz, D.; Sosnowski, S.; D’hooge, D. R.; Szymanski, R.; Reyniers, M.-F.; Marin, G. B.; Matyjaszewski, K., Origin of the Difference between Branching in Acrylates Polymerization under Controlled and Free Radical Conditions: A Computational Study of Competitive Processes. Macromolecules 2011, 44 (21), 8361-8373.

37. Konkolewicz, D.; Krys, P.; Matyjaszewski, K., Explaining Unexpected Data via Competitive Equilibria and Processes in Radical Reactions with Reversible Deactivation. Accounts of Chemical Research 2014, 47 (10), 3028-3036.

38. Hamzehlou, S.; Ballard, N.; Reyes, Y.; Aguirre, A.; Asua, J. M.; Leiza, J. R., Analyzing the discrepancies in the activation energies of the backbiting and [small beta]-scission reactions in the radical polymerization of n-butyl acrylate. Polymer Chemistry 2016, 7 (11), 2069-2077.

39. Vandenbergh, J.; Junkers, T., Macromonomers from AGET Activation of Poly(n-butyl acrylate) Precursors: Radical Transfer Pathways and Midchain Radical Migration. Macromolecules 2012, 45 (17), 6850-6856. 
40. Van Steenberge, P. H. M.; Vandenbergh, J.; Reyniers, M.-F.; Junkers, T.; D’hooge, D. R.; Marin, G. B., Kinetic Monte Carlo Generation of Complete Electron Spray Ionization Mass Spectra for Acrylate Macromonomer Synthesis. Macromolecules 2017, 50 (7), 2625-2636.

41. Chiefari, J.; Jeffery, J.; Mayadunne, R. T. A.; Moad, G.; Rizzardo, E.; Thang, S. H., Chain Transfer to Polymer: A Convenient Route to Macromonomers. Macromolecules 1999, 32 (22), 7700-7702.

42. Junkers, T.; Barner-Kowollik, C., Optimum Reaction Conditions for the Synthesis of Macromonomers Via the High-Temperature Polymerization of Acrylates. Macromolecular Theory and Simulations 2009, 18 (7-8), 421-433.

43. Peck, A. N. F.; Hutchinson, R. A., Secondary Reactions in the High-Temperature Free Radical Polymerization of Butyl Acrylate. Macromolecules 2004, 37 (16), 5944-5951.

44. Jakubowski, W.; Matyjaszewski, K., Activators Regenerated by Electron Transfer for AtomTransfer Radical Polymerization of (Meth)acrylates and Related Block Copolymers. Angewandte Chemie 2006, 118 (27), 4594-4598.

45. Xia, J.; Gaynor, S. G.; Matyjaszewski, K., Controlled/“Living” Radical Polymerization. Atom Transfer Radical Polymerization of Acrylates at Ambient Temperature. Macromolecules 1998, 31 (17), 5958-5959.

46. Chiefari, J.; Chong, Y. K.; Ercole, F.; Krstina, J.; Jeffery, J.; Le, T. P. T.; Mayadunne, R. T. A.; Meijs, G. F.; Moad, C. L.; Moad, G.; Rizzardo, E.; Thang, S. H., Living Free-Radical Polymerization by Reversible Addition-Fragmentation Chain Transfer: The RAFT Process. Macromolecules 1998, 31 (16), 5559-5562.

47. Chong, Y. K.; Krstina, J.; Le, T. P. T.; Moad, G.; Postma, A.; Rizzardo, E.; Thang, S. H., Thiocarbonylthio Compounds [SC(Ph)S-R] in Free Radical Polymerization with Reversible Addition-Fragmentation Chain Transfer (RAFT Polymerization). Role of the Free-Radical Leaving Group (R). Macromolecules 2003, 36 (7), 2256-2272.

48. Schröder, K.; Mathers, R. T.; Buback, J.; Konkolewicz, D.; Magenau, A. J. D.; Matyjaszewski, K., Substituted Tris(2-pyridylmethyl)amine Ligands for Highly Active ATRP Catalysts. ACS Macro Letters 2012, 1 (8), 1037-1040.

49. Schröder, K.; Konkolewicz, D.; Poli, R.; Matyjaszewski, K., Formation and Possible Reactions of Organometallic Intermediates with Active Copper(I) Catalysts in ATRP. Organometallics 2012, 31 (22), 7994-7999.

50. Wang, Y.; Soerensen, N.; Zhong, M.; Schroeder, H.; Buback, M.; Matyjaszewski, K., Improving the "Livingness" of ATRP by Reducing Cu Catalyst Concentration. Macromolecules 2013, 46 (3), 683-691.

51. Matyjaszewski, K.; Woodworth, B. E., Interaction of Propagating Radicals with Copper(I) and Copper(II) Species. Macromolecules 1998, 31 (15), 4718-4723.

52. Poli, R., Relationship between One-Electron Transition-Metal Reactivity and Radical Polymerization Processes. Angewandte Chemie International Edition 2006, 45 (31), 5058-5070.

53. Allan, L. E. N.; Perry, M. R.; Shaver, M. P., Organometallic mediated radical polymerization. Progress in Polymer Science 2012, 37 (1), 127-156.

54. Wayland, B. B.; Peng, C.-H.; Fu, X.; Lu, Z.; Fryd, M., Degenerative Transfer and Reversible Termination Mechanisms for Living Radical Polymerizations Mediated by Cobalt Porphyrins. Macromolecules 2006, 39 (24), 8219-8222. 
55. Wang, F.-S.; Yang, T.-Y.; Hsu, C.-C.; Chen, Y.-J.; Li, M.-H.; Hsu, Y.-J.; Chuang, M.-C.; Peng, C.-H., The Mechanism and Thermodynamic Studies of CMRP: Different Control Mechanisms Demonstrated by Coll(TMP), Coll(salen*), and Coll(acac)2 Mediated Polymerization, and the Correlation of Reduction Potential, Equilibrium Constant, and Control Mechanism. Macromolecular Chemistry and Physics 2016, 217 (3), 422-432.

56. Debuigne, A.; Poli, R.; Jérôme, C.; Jérôme, R.; Detrembleur, C., Overview of cobaltmediated radical polymerization: Roots, state of the art and future prospects. Progress in Polymer Science 2009, 34 (3), 211-239.

57. Soerensen, N.; Schroeder, H.; Buback, M., SP-PLP-EPR Measurement of Cull-Mediated ATRP Deactivation and Cul-Mediated Organometallic Reactions in Butyl Acrylate Polymerization. Macromolecules 2016, 49 (13), 4732-4738.

58. Ribelli, T. G.; Rahaman, S. M. W.; Daran, J.-C.; Krys, P.; Matyjaszewski, K.; Poli, R., Effect of Ligand Structure on the Cull-R OMRP Dormant Species and Its Consequences for Catalytic Radical Termination in ATRP. Macromolecules 2016, 49 (20), 7749-7757.

59. Pan, X.; Tasdelen, M. A.; Laun, J.; Junkers, T.; Yagci, Y.; Matyjaszewski, K., Photomediated controlled radical polymerization. Progress in Polymer Science 2016, 62, 73-125.

60. Williams, V. A.; Ribelli, T. G.; Chmielarz, P.; Park, S.; Matyjaszewski, K., A Silver Bullet: Elemental Silver as an Efficient Reducing Agent for Atom Transfer Radical Polymerization of Acrylates. Journal of the American Chemical Society 2015, 137 (4), 1428-1431.

61. De Paoli, P.; Isse, A. A.; Bortolamei, N.; Gennaro, A., New insights into the mechanism of activation of atom transfer radical polymerization by $\mathrm{Cu}(\mathrm{i})$ complexes. Chemical Communications 2011, 47 (12), 3580-3582.

62. Krys, P.; Wang, Y.; Matyjaszewski, K.; Harrisson, S., Radical Generation and Termination in SARA ATRP of Methyl Acrylate: Effect of Solvent, Ligand, and Chain Length. Macromolecules 2016, 49 (8), 2977-2984.

63. Wang, Y.; Zhong, M.; Zhang, Y.; Magenau, A. J. D.; Matyjaszewski, K., Halogen Conservation in Atom Transfer Radical Polymerization. Macromolecules 2012, 45 (21), 8929 8932.

64. Fantin, M.; Isse, A. A.; Bortolamei, N.; Matyjaszewski, K.; Gennaro, A., Electrochemical approaches to the determination of rate constants for the activation step in atom transfer radical polymerization. Electrochimica Acta 2016, 222, 393-401.

65. Kaur, A.; Ribelli, T. G.; Schröder, K.; Matyjaszewski, K.; Pintauer, T., Properties and ATRP Activity of Copper Complexes with Substituted Tris(2-pyridylmethyl)amine-Based Ligands. Inorganic Chemistry 2015, 54 (4), 1474-1486.

66. Nikitin, A. N.; Hutchinson, R. A.; Wang, W.; Kalfas, G. A.; Richards, J. R.; Bruni, C., Effect of Intramolecular Transfer to Polymer on Stationary Free-Radical Polymerization of Alkyl Acrylates, 5 - Consideration of Solution Polymerization up to High Temperatures. Macromolecular Reaction Engineering 2010, 4 (11-12), 691-706.

ToC Graphic 


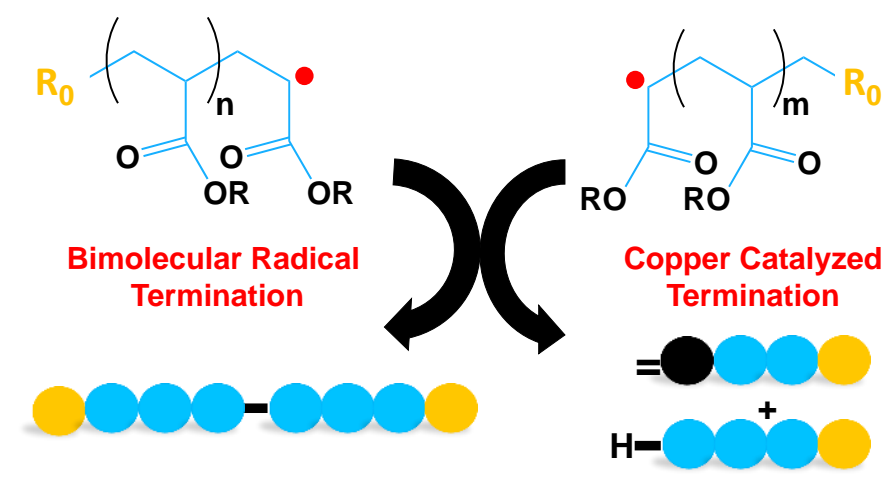

Disproportionation or Combination? 